\title{
Defining deep decarbonization pathways for Switzerland: An economic evaluation
}

Babonneau, Frédéric, Philippe Thalmann and Marc Vielle, "Defining deep decarbonization pathways for Switzerland: an economic evaluation", Climate Policy, Published online 07 Nov. 2016 (DOI: 10.1080/14693062.2016.1227952)

\section{Introduction}

As part of the international Deep Decarbonization Pathways Project (DDPP), ${ }^{1}$ this paper explores simulation results of deep decarbonization pathways for Switzerland. The DDPP is an international collaborative initiative aiming at understanding and showing how individual countries might define a roadmap to 2050 that paves the way to reaching a low carbon economy, compatible with keeping the global mean temperature increase below $2^{\circ} \mathrm{C}$. For a review of national deep decarbonization analyses, see Pye and Bataille (2016). This paper describes the main insights and results of the Swiss analysis.

Deep decarbonisation will be a special challenge for Switzerland and being able to meet it could inspire many countries in similar conditions. To begin with, Switzerland does not have the usual options for decarbonisation: it produces its electricity essentially free of carbon and has very little heavy industry left. In addition, housing is overwhelmingly rental (about 60\%) which raises the problem of split incentives regarding energy refurbishments. Finally, Switzerland decided to phase out its nuclear power plants in the wake of the Fukushima disaster, with no clear plan of how to replace that source of about $40 \%$ of its electricity generation. Clearly, leading such an economy on a DDP will require a suitable set

1 http://www.deepdecarbonization.org 
of policy instruments and very high carbon prices. This paper proposes one set of plausible paths.

Plausible DDPs are simulated with the computable general equilibrium model GEMINI-E3. We explore three DDP scenarios that assume a 1 ton $\mathrm{CO}_{2}$ emissions target in 2050 per Swiss inhabitant, which amounts to $76 \%$ abatement with respect to 1990 levels and is thus considered compatible with the $2^{\circ} \mathrm{C}$ target. We compare these scenarios with a reference scenario that includes only energy and climate policies already decided. The three DDPs differ in their assumptions about the availability of Carbon Capture and Storage (CCS) technologies and a cap on electricity consumption.

The paper is structured as follows: In Section 2, we discuss the literature on DDPs with emphasis on results specially relevant for countries such as Switzerland and we introduce the Swiss climate policy. Section 3 briefly presents the GEMINI-E3 model used to perform the economic simulations. Section 4 details the storylines and the assumptions of possible deep decarbonization pathway scenarios. Section 5 provides the results and analysis, finally, the last section concludes.

\section{Literature on deep decarbonization pathways and Swiss climate policy}

Literature on deep decarbonization pathways. Following the IPCC conclusions and the urgent need to address the rapid decarbonization pathways of our economies by 2050, several analyses have examined scenarios that achieved significant reductions in greenhouse gas emissions. At a worldwide level, Edenhofer et al. (2010) performed a models comparison of global emissions trajectories in line with the $2^{\circ} \mathrm{C}$ target. They concluded that such trajectories are feasible technically and economically, but that the availability of some technological options is crucial, such as CCS and biomass. At more regional or country levels, Deetman et al. (2013) explored several options for Europe that reduce emissions by $65 \%$ by 2050 below 1990 levels using bottom-up modelling. They stressed that the contribution of the power 
generation sector is decisive for reaching deep emission reductions. Ashina et al. (2012) developed a roadmap of a low-carbon society in Japan by 2050 using the AIM/Backcasting model. They point out that large investments are needed, particularly in the residential, commercial, and transport sectors, as well as early action to achieve the deployment of innovative technologies. More recently, the DDP project (Mathy et al., 2016, Bataille et al., 2016) defines the three main pillars of energy system transformation for all DDPs: 1) energy efficiency; 2) decarbonization of electricity generation and fuels; and 3) switching end use to low-carbon supplies.

Swiss climate performance and policy. Compared to other industrialized countries, $\mathrm{CO}_{2}$ emissions of Switzerland are relatively low, with 5.34 tons per inhabitant in 2013 (Swiss Federal Office for the Environment, 2015). This reflects essentially non-fossil electricity generation (57.9\% hydropower, 36.4\% nuclear, 1.7\% new renewables in 2013, Swiss Federal Office of Energy, 2013) and a small share of heavy industry (3.7\% of GDP in 2013). $\mathrm{CO}_{2}$ emissions peaked in 1991 (4.7\% above the 1990 level) and then declined quite smoothly to 2.0\% below the 1990 level in 2013 (Swiss Federal Office for the Environment, 2015). Over those 23 years, real GDP increased by $42 \% . \mathrm{CO}_{2}$ emissions from transportation increased by $12 \%$, which was more than offset by decreases in all other sectors. The road transport sector has been treated very leniently by climate policy, possibly due to preexisting ordinary fuel taxes equivalent to about $360 \mathrm{CHF}$ per ton $\mathrm{CO}_{2}$. There was some compensation of its emissions funded by a $0.015 \mathrm{CHF}$ surcharge on motor fuels between 2005 and 2012. There is now the obligation for importers of these fuels to compensate $2 \%$ of the implicit $\mathrm{CO}_{2}$ emissions in $2014-15,5 \%$ in $2016-17,8 \%$ in $2018-19$ and $10 \%$ in 2020 through mitigation in other sectors. For the other sectors, climate policy was first based on voluntary commitments, and it still depends on voluntary efforts and on the effects of policies in other areas (e.g., energy efficiency, clean air, land use, agriculture and forestry, public transportation, etc.). Nevertheless, a $\mathrm{CO}_{2}$ tax was introduced for heating and process fuels, including natural gas, in 2008. For two years, it was set at $12 \mathrm{CHF} /$ ton $\mathrm{CO}_{2}$, then for four years at $36 \mathrm{CHF} /$ ton (which 
amounted to a $15 \%$ tax on heating oil and $8 \%$ on natural gas), at $60 \mathrm{CHF} /$ ton in 2014-15 and $84 \mathrm{CHF} /$ ton since 2016. Two-thirds of the revenues of the $\mathrm{CO}_{2}$ tax are refunded to households and firms and one-third is used to subsidize (lightly) measures that reduce $\mathrm{CO}_{2}$ emissions from buildings (Buildings refurbishment program). Energy-intensive firms are exempted from the $\mathrm{CO}_{2}$ tax in exchange for (hardly binding) reduction commitments of $\mathrm{CO}_{2}$ emissions. For more details on Swiss climate policy and performance, see FOEN (2014).

\section{The GEMINI-E3 Model}

GEMINI-E3 is a multi-country, multi-sector, recursive computable general equilibrium model (Bernard \& Vielle, 2008). The standard model is based on the assumption of perfect markets, both macroeconomic markets, such as those for capital and international trade (with endogenous real rate of interest and real exchange rate), and microeconomic or sector markets (goods, factors of production, etc.).

The current version is built on the Swiss input-output table 2008 (Nathani et al., 2011) and on the GTAP database 8 (Narayanan et al., 2012) for the other countries. The industrial classification used in this study is presented in Table 1. Regarding spatial decomposition, GEMINI-E3 describes five country/regions: Switzerland, European Union, USA, BRIC (Brazil, Russia, India, and China) and the rest of the world.

\section{Table 1: Industrial classifications}

\subsection{Energy demand}

Domestic energy demand is equal to the sum of the energy consumed by firms as a production factor and of the energy consumed by households as a final good. Energy consumption by firms and households is split in two parts, for transportation and housing purposes. In each part, energy can be substituted by spending more on a capital good represented by vehicles in 
the first case and by buildings in the second one, i.e., by purchasing more energy-efficiency but also more expensive vehicles and buildings.

\subsection{Energy supply}

Switzerland imports all of its coal, natural gas, and crude oil, so only electricity generation needs to be modelled. It is represented by a nested CES function, including - besides fossil fuels, and nuclear and hydraulic plants - the new capacities installed in the renewable technologies. Power generation is separated from the other activities (transmission and distribution) that appear through their factors of production at the top of the nesting structure. As labor is of negligible importance for power generation, we retain only two factors of production, capital and fuels (only capital for renewables).

\section{Definition of reference and DDP scenarios}

In this section, we introduce the storylines, as well as the main assumptions, used for the definition of the reference scenario and the three DDP ones that are analyzed in the next section with GEMINI-E3.

\subsection{Defining storylines}

Scenarios considered in the present analysis are the following:

- The "reference scenario" assumes that Switzerland will achieve by 2020 a $20 \%$ reduction of its $\mathrm{CO}_{2}$ emissions relative to 1990 levels, using instruments that have already been implemented. After 2020, we suppose these instruments are maintained at their current levels without any additional measures;

- In a set of three "DDP scenarios", we assume that Switzerland will reach the 1 ton $\mathrm{CO}_{2}$ per capital target by 2050. The variants differ only in their assumptions regarding the availability of CCS technologies and on a possible cap on electricity consumption. 
Below, we focus on assumptions common to the four scenarios, while specific ones are given in Section 5. According to the Swiss climate policy, the defined $\mathrm{CO}_{2}$ targets concern emissions from all sources except international aviation. In addition, for the sake of simplification, we assume in all scenarios that no climate policy is implemented in the rest of the world. This probably raises the required carbon price, as no carbon trading with other regions is allowed and technology spillovers will be less.

Up to 2020, the DDP and reference scenarios rely on the same set of standard assumptions, mainly drawn from the Swiss climate policy (see FOEN, 2014). More precisely, we assume that the following measures and instruments are implemented up to 2020:

1. The path for nuclear phase-out is applied;

2. The Buildings refurbishment program, which provides moderate subsidies for the energy improvement of existing buildings, is extended up to 2020;

3. The cap on the $\mathrm{CO}_{2}$ emissions of new cars, which was lowered to $130 \mathrm{gCO}_{2} / \mathrm{km}$ in 2015 , is gradually lowered to $95 \mathrm{gCO}_{2} / \mathrm{km}$ in 2020 ;

4. Electric vehicles significantly penetrate the passenger cars market, as well as that of other road transport vehicles;

5. No CCS technology is available;

6. A Swiss emission trading scheme (ETS) for energy-intensive industries is implemented. The cap is lowered every year by a constant factor (1.74\%). GEMINI-E3's sectors that participate in the ETS are the electricity generation sector and the energy-intensive industries;

7. The existing $\mathrm{CO}_{2}$ tax is raised following the official rule, i.e., whenever the abatement level attained is not sufficient to reach the $\mathrm{CO}_{2}$ target in 2020;

8. The 0.015 CHF surcharge on transport fuel prices, levied between 2005 and 2012 is replaced by a new instrument in 2014: oil importers must offset domestically a share of the $\mathrm{CO}_{2}$ emissions from transport fuel use. The shares were set at $2 \%$ in 2014-2015, $5 \%$ in $2016-2017,8 \%$ in $2018-2019$, and $10 \%$ in 2020 . The offset is funded by a levy that shall not exceed 0.05 CHF per liter of fuel. 
After 2020, DDP scenarios diverge from the reference one, which does not integrate new targets on $\mathrm{CO}_{2}$ emissions nor assume any new regulation on energy efficiency, i.e., it freezes the carbon prices to their 2020 levels. Therefore, we use the following assumptions in the reference scenario:

1. The carbon prices (ETS price and $\mathrm{CO}_{2}$ tax) and the levy charged on transport fuels remain constant at their 2020 level;

2. The budget of the Buildings refurbishment program remains constant at its 2020 level;

3. The emissions cap for new cars remains constant at its 2020 level of $95 \mathrm{gCO}_{2} / \mathrm{km}$.

The DDP scenarios assume a much more stringent climate policy that will be achieved mainly through the implementation of a universal uniform carbon tax. However, as the scenario is based on significant shifts in climate policy, we believe that new technological options need to be considered. The DDP scenario will assume the following:

1. The CCS option becomes available in 2025;

2. The Buildings refurbishment program is terminated in 2020;

3. The cap on the $\mathrm{CO}_{2}$ emissions of new cars is lowered further after 2020 , down to 35 $\mathrm{gCO}_{2} / \mathrm{km}$ in 2050;

4. The $\mathrm{CO}_{2}$ prices and the levy charged on transport fuels are replaced by a uniform carbon tax applied to all fossil energy consumption and set at a level that guarantees reaching the $\mathrm{CO}_{2}$ target by 2050 .

\subsection{Common assumptions for DDP and reference scenarios}

To simulate the evolution of the economy until 2050, GEMINI-E3 uses forecasts of population growth, GDP and energy prices, as well as assumptions regarding electricity generation as detailed below.

Demography. We use the evolution of the Swiss population as defined by the A-17-2010 scenario from the Swiss Federal Office of Statistics (2010). In 2050, 9.8 million inhabitants will live in Switzerland, 25\% more than in 2010. 
For the rest of the world, we assume the "median-fertility variant" of the 2010 United Nations forecast (United Nations, 2011), which has the world population reach 9.27 billion inhabitants.

GDP growth. We compute the potential Swiss GDP growth rate by multiplying the labour force derived from the demographic scenario by labour productivity. We assume that labour productivity increases by $0.5 \%$ per year over the whole period. For the rest of the world, we apply a similar methodology. Table 2 shows the resulting GDP growth rates in the reference scenario.

\section{Table 2: Annual GDP growth rate}

World energy prices. Energy price assumptions are also drawn from the World Energy Outlook (WEO) 2013 (International Energy Agency, 2013). Since scenarios presented in this paper assume that only Switzerland implements a climate policy, we retain the "current policies scenario" of the WEO 2013. As it goes only until 2035, we assume that energy prices will continue to grow and converge to a growth rate of $0.7 \%$ per year at the end of the simulation horizon (2050). Table 3 shows the energy prices used in the reference scenario.

\section{Table 3: Fossil fuel import prices (USD 2012 per unit) - Source: WEO 2013 (International Energy Agency, 2013) (Current policies scenario)}

Electricity generation. In May 2011, the Swiss Federal government decided, after the Fukushima nuclear disaster in Japan, to gradually decommission all six nuclear power plants, which contribute $38 \%$ of Swiss electricity generation in 2014. The operator of the Mühleberg power plant already decided to cease all electrical generation in 2019 . The strategy for the

other five plants is to decomission them when they reach the end of their safe service life and not to replace them with new ones. The Swiss government did not set the end of their lifetime. 
We assume a lifetime of 60 years, which implies that the most recent plant will be taken off the grid in 2044.

Table 4 shows the expected generation potential for new renewables under plausible economic, environmental and political feasibility assumptions. The main source is a publication of the Swiss Federal Office of Energy (2012) partly revised by the experts of the consultancy INFRAS. The electricity generation prices for new renewable capacities are given in Table 5. The expected decline in generation costs guarantees that the full potentials will be used.

\section{Table 4: Potentials of new renewables in 2050 (GWh) - Source: Swiss Federal Office of Energy (2012)}

Table 5: Electricity generation costs (Swiss cents per kWh) - Source: Prognos (2012)

\subsection{Specific assumptions of the reference scenario}

Transportation. We assume that the $\mathrm{CO}_{2}$ emissions cap for new cars of 130 grams per kilometer in 2015 will be lowered linearly to 95 grams in 2020 and then stay at that level. The regulation remains constant afterwards. For the other types of vehicles we assume that specific $\mathrm{CO}_{2}$ emissions decline at the same rate. We suppose that electric cars will penetrate the market of passenger cars in the forthcoming decades, and that their share will be 5\% in 2020 and $40 \%$ in 2050 . For other road vehicles, the share of electric motors reaches $30 \%$ in 2050 (vehicles on tracks are nearly entirely electrical since the middle of the $20^{\text {th }}$ century).

Buildings sector. The Buildings refurbishment program, initiated in 2010 by the Confederation and the cantons, aims at significantly reducing the energy consumption and the $\mathrm{CO}_{2}$ emissions of Swiss buildings. Around $40 \%$ of the energy consumption and $\mathrm{CO}_{2}$ emissions in Switzerland are generated by the buildings sector and about 1.5 million houses and buildings, or about $80 \%$, require substantial energy retrofit. The program has two parts in 
the period 2010-2019. Part A includes federal subsidies for mainly thermal insulation works, while Part B encourages investments in renewable energy use in buildings. In the reference scenario, we assume that budget of the Buildings refurbishment program remains constant after 2020, i.e., that 200 million CHF will be spent in subsidies every year. In the following, we estimate the direct contribution of Part $\mathrm{A}$ on $\mathrm{CO}_{2}$ savings up to 2050 based on 2011-2013 statistics.

To estimate the global impact of the Buildings refurbishment program from 2011 to 2050, we made the following assumptions:

- The budget for federal subsidies will be maintained at 200 million CHF per year between 2014 and 2050;

- The efficiency ratio (i.e., $\mathrm{CO}_{2}$ savings per $\mathrm{CHF}$ ) of the implemented measures will decrease by $50 \%$ between 2014 and 2050, i.e., the rate of energy efficiency improvement declines through time.

Table 6 reports the resulting $\mathrm{CO}_{2}$ savings. The column "Cumulative effective $\mathrm{CO}_{2}$ savings" indicates the $\mathrm{CO}_{2}$ savings in the corresponding year obtained by current and past retrofit, subsidized by the Buildings refurbishment program. The analysis leads to $46.71 \mathrm{Mt}$ of $\mathrm{CO}_{2}$ savings for the full program duration (2011-2050).

\section{Table 6: Forecasted $\mathrm{CO}_{2}$ savings resulting from the Buildings refurbishment program}

\subsection{Specific assumptions of the DDP scenarios}

Transportation. In the DDP scenarios, we assume that the cap on $\mathrm{CO}_{2}$ emissions for new cars is reinforced after 2020, contrary to the reference scenario, declining gradually to 35 grams per kilometer in 2050, which is in line with the assumption used in the "New Energy Policy" scenario of the Energy Perspectives (Prognos, 2012). This cap includes all new car, 
including electric ones. The same assumption is made for the other types of vehicles in relative terms.

Carbon capture and storage. The $\mathrm{CO}_{2}$ sequestration potential is significant in Switzerland, at around 2680 million tons (Diamond et al., 2010). The IEA evaluates the cost of $\mathrm{CO}_{2}$ capture on average at 80 USD per ton of $\mathrm{CO}_{2}$ for natural gas-fired power plants (Finkenrath, 2011). Transportation costs vary between 2 and 6 USD per ton for $2 \mathrm{Mt} \mathrm{CO}_{2}$ transported over $100 \mathrm{~km}$ according to International Energy Agency (2008). The same publication estimates the sequestration cost in deep saline aquifers in Europe between 1.90 and 6.20 USD per ton of $\mathrm{CO}_{2}$. In this study, we suppose that CCS is implemented in Switzerland from 2025 at a total cost of $100 \mathrm{USD}_{2012}$.

\section{Simulations results}

In this section, we detail the first simulation results of the reference scenario, and then focus on the DDP scenarios. The three variants of the DDP scenario are:

- "Standard" DDP scenario, as defined in the previous section;

- DDP scenario without CCS option;

- DDP scenario with a cap on electricity consumption (to be defined later).

The simulation results for all scenarios on $\mathrm{CO}_{2}$ emissions by sectors, electricity generation by energies, and electricity consumption by uses are displayed in Figures 1, 2 and 3, respectively.

\subsection{The reference scenario}

Table 7 shows the $\mathrm{CO}_{2}$ prices and the levy charged on fuels used for transportation, as they are computed by the model to meet the emissions and compensation targets of the reference scenario. In 2020, a very low transport fuels levy of around 2 Swiss cents per liter is sufficient to fund the $10 \%$ carbon offset for imported fuels. $\mathrm{CO}_{2}$ emissions from the road transportation sector are thus not affected by the levy, and $\mathrm{CO}_{2}$ abatement is provided by other sectors: households, services and industry (Figure 1). The $\mathrm{CO}_{2}$ tax at $60 \mathrm{CHF}$ defined for the year 
2014 is sufficient to reach the $20 \%$ abatement target by 2020 . In that context, the ETS market is in equilibrium at a price of $40 \mathrm{CHF}$ per ton $\mathrm{CO}_{2}$ in 2020. The main demand comes from the deployment of gas turbines in electricity generation, with 4 TWh generated in 2020.

\section{Table 7: $\mathrm{CO}_{2}$ prices and other levies $\left(\mathrm{CHF}_{2013}\right)$ - reference scenario}

Beyond 2020, the reference scenario freezes the carbon prices and transport fuels levy at the levels they had to attain for the 2020 targets. With these assumptions, $\mathrm{CO}_{2}$ emissions (including international aviation) are about $29.2 \mathrm{Mt} \mathrm{CO}_{2}$ in 2050 , which is $22.5 \%$ below 2020 levels (Figure 1). Without the emissions from international aviation, this represents 2.5 tons of $\mathrm{CO}_{2}$ per capita. All sectors contribute to the decline of $\mathrm{CO}_{2}$ emissions except the ETS sectors, for which emissions increase by $14 \%$ between 2007 and 2050 following the deployment of electricity generation from natural gas. Over the same period, $\mathrm{CO}_{2}$ emissions from road transport decrease by $31 \%$ thanks to electric vehicles, while emissions from the residential sector decrease by $56 \%$ due to the cumulative effects of the Buildings refurbishment program.

\section{Figure 1: Swiss $\mathrm{CO}_{2}$ emissions $\left(\mathrm{Mt} \mathrm{CO}_{2}\right)$}

In electricity generation nuclear power is gradually replaced by natural gas and new renewables (Figure 2). Total electricity generation reaches $78 \mathrm{TWh}$ in 2050. Electricity consumption increases by $0.3 \%$ per year over the period of simulation. This increase results mainly from the deployment of electric vehicles and the substitution of fossil energy by electricity in heating systems (e.g., heat pumps).

Figure 2: Swiss electricity generation (TWh) 


\subsection{First DDP scenario}

This scenario has an emissions target of 1 ton of $\mathrm{CO}_{2}$ per capita in 2050. It is attained by implementing, after 2020, a uniform $\mathrm{CO}_{2}$ price that rises gradually and endogenously to meet the target. We find that a tax rate of $1556 \mathrm{CHF}$ per ton of $\mathrm{CO}_{2}$ is needed in 2050. In the last decade, the $\mathrm{CO}_{2}$ price is multiplied by two (Table 8), which shows the stringency of that target. A similar result is found with models used to analyse the European strategy in the EMF28 exercise (Weyant et al. 2013). The welfare cost is equivalent to a decrease of $1.7 \%$ of household consumption in 2050. It is relatively small because the revenues of the large $\mathrm{CO}_{2}$ tax are refunded lump-sum to households.

\section{Table 8: $\mathrm{CO}_{2}$ prices and other levies $\left(\mathrm{CHF}_{2013}\right)$ and welfare cost - DDP scenario}

Simulation results indicate that $\mathrm{CO}_{2}$ emissions decrease linearly from 2007 to 2050 . The 2020 committed target appears to be consistent with the DDP target. All sectors contribute to the abatement except international aviation, which is not taxed in the DDP scenario and whose emissions are not counted in the 1 ton target.

By assuming that all emissions from natural gas power plants are sequestered after 2025 , this represents $77 \mathrm{Mt}$ of $\mathrm{CO}_{2}$ for $2025-2050$ or $3 \%$ of the Swiss sequestration capacity. The decarbonization of the Swiss economy is thus partly realized through the use of more electricity combined with CCS, allowing the production of electricity with natural gas free of $\mathrm{CO}_{2}$, and through the use of new renewables whose potential is fully used in 2050. In 2050, $90 \mathrm{TWh}$ of electricity are produced, which represents a $15 \%$ increase relative to the reference scenario. Electricity generation from natural gas is equal to $21 \mathrm{TWh}$.

It is worth noting that, as shown in Figure 3, electricity consumption for transportation (without railways) represents 15 TWh in 2050, which is quite substantial. 


\section{Figure 3: Swiss electricity consumption (TWh)}

\subsection{DDP scenario without CCS}

We observed in the previous DDP scenario that CCS represents an important contribution to $\mathrm{CO}_{2}$ abatement. However, $\mathrm{CCS}$ is surrounded by several uncertainties related mainly to technological issues and social acceptability, especially in Switzerland, where geological conditions are most favorable in regions close to population centers. Therefore, we simulate a DDP scenario in which we suppose that CCS is not implemented in electricity generation. In this case, $\mathrm{CO}_{2}$ emissions from gas power plants are taxed like any other $\mathrm{CO}_{2}$ emissions.

The first DDP scenario uses up the full potential of renewables in 2050, so any additional electricity generation needs natural gas power plants. Since, this induces carbon emissions, a much higher $\mathrm{CO}_{2}$ tax is now needed to attain the target of 1 ton of $\mathrm{CO}_{2}$ per capita in 2050, 2650 CHF (Table 9). This implies a welfare loss of $1.9 \%$ of household consumption in 2050 .

\section{Table 9: $\mathrm{CO}_{2}$ prices and other levies $\left(\mathrm{CHF}_{2013}\right)$ and welfare cost - DDP scenario without CCS}

The carbon taxation of power plants using natural gas increases the electricity price, limiting the substitution of fossil fuels by electricity. Electricity generation reaches $78 \mathrm{TWh}, 12 \mathrm{TWh}$ below the scenario with CCS. Regarding $\mathrm{CO}_{2}$ emissions, the share of these emissions coming from ETS sectors (including electricity generation) increases, which, of course, requires more abatement from the other sectors (see Figure 1). Emissions from electricity generation are equal to $2.4 \mathrm{Mt} \mathrm{CO}_{2}$, or $25 \%$ of total emissions (excluding international aviation). 


\subsection{DDP scenario with a cap on electricity consumption}

One of the main conclusions of the DDP scenario analysis is that the decarbonization of the Swiss economy comes with an increase in electricity generation partly produced from natural gas. This result, however, raises two issues. First, this option is cost-effective only with CCS implementation, which is, at the same time, highly uncertain. Secondly, the significant induced imports of natural gas stand in contradiction to the Swiss energy strategy, which emphasises the security of energy supply.

In order to avoid this undesirable side effects of the DDP scenario, we consider a new scenario with a cap on long-term electricity consumption. Indeed, we refer to the planned update of the Swiss Energy Act, which states that per capita electricity consumption must decrease by 3\% in 2020 and by $13 \%$ in 2035 with respect to 2000 levels. We extend this to a $18 \%$ reduction in 2050 (considering that population is expected to grow by $36 \%$ between 2000 and 2050). Therefore, in 2050 electricity consumption would be less than $63 \mathrm{TWh}$. The scenario assumes that this target is implemented through additional indirect taxation of electricity consumption for all uses (intermediate and final).

As can be seen in Figure 3, electricity consumption would remain roughly constant throughout the simulation period. It can be supplied by hydro and other renewables without any natural gas contribution. As a consequence, the required carbon price increases much less than in the DDP scenario without CCS, to 1963 CHF in 2050 (Table 10). This is only $26 \%$ higher than in the DDP scenario without cap. On the other hand, the cap on electricity consumption requires a large increase of electricity taxation, with an indirect tax rate equal to $88 \%$ in 2050 . Combining a carbon tax and a tax on electricity consumption slightly decreases the welfare cost with respect to the first DDP scenario, to $1.5 \%$ in 2050 . This can be explained by the reduced imports of natural gas. under the balanced trade constraint. This creates a trade revenue surplus, i.e., less exports are required to offset import and consumption can increase. A similar result effect was evidenced with another Swiss CGE model, GENESwIS (Maire et al. 2015). 


\section{Table 10: $\mathrm{CO}_{2}$ prices and other levies $\left(\mathrm{CHF}_{2013}\right)$ and welfare cost - DDP scenario with a cap on electricity consumption}

\section{Conclusion}

This analysis aimed at simulating deep decarbonization pathways for a country that cannot count on large sectors emitting significantly $\mathrm{CO}_{2}$, i.e., where it is emitted by a myriad of small sources, mainly buildings and vehicles. Furthermore, a country that is small, heavily interlinked with the rest of the world and entirely devoid of fossil energy sources. To show how deep decarbonization was still feasible and estimate what it would take and cost, we used the GEMINI-E3 model adapted to account for existing Swiss conditions and policies.

These simulations provide several insights. First, the objective of 1 ton of $\mathrm{CO}_{2}$ per capita in the next 35 years is quite challenging, especially when nuclear power is to be phased-out by 2044. Nevertheless, it is possible to design feasible pathways. With CCS deployment, cumulative welfare losses (without discounting) can be limited to $1 \%$ of household consumption. In 2050, the welfare loss represents $1.7 \%$ of household consumption, which is much lower than the estimates of the FP7 AMPERE project (E3MLab and ICCS, 2013) that range from $2 \%$ to $9.5 \%$ GDP reduction for the European Union. At the end of the period, the $\mathrm{CO}_{2}$ tax is equal to $1556 \mathrm{CHF}$. This price is high in comparison with those found in the EMF28 exercise (Weyant et al., 2013) for European countries, where the median value is $521 € / \mathrm{CO}_{2}$ with a range of [240 - $1127 € / \mathrm{CO}_{2}$ ] by 2050 . However, it is consistent with previous analyses of ambitious climate policies for Switzerland (Böhringer and Müller, 2014, Bretschger and Zhang, 2016). The main reason for this is that Switzerland lacks the classical sectors where $\mathrm{CO}_{2}$ can be mitigated at moderate cost (e.g., coal fired electricity generation, heavy industry). This has the effect, on the other hand, to limit the adverse welfare impact, 
because fossil energy amounts, after all, to only a small share of production costs and household budgets.

In that context, the decarbonization of the Swiss economy is achieved through energy efficiency improvements but also through the substitution of fossil energy by carbon-free electricity. As the Swiss renewable potential is not sufficient to satisfy all electricity demand, the model shows the deployment of CCS associated with combined cycle gas turbines. This penetration of CCS technologies is consistent with other EU studies (E3MLab and ICCS, 2013; Weyant et al., 2013), in which CCS is combined with a growing share of European electricity generation.

Without CCS, the cost of the DDP scenario rises, but this increase is mitigated by gains coming from reduced imports of natural gas for power generation. The welfare cost reaches $1.9 \%$ in 2050 .

Finally, we simulated a scenario that combines caps on carbon emissions and on electricity consumption. In this case, Swiss electricity generation remains free of carbon and based on hydro and other renewables. The welfare cost is comparable to the one computed in the first DDP scenario, but would result in a less energy-intensive economy that does not rely on imports of natural gas.

\section{References}

Ashina, S., Fujino, J., Masui, T., Ehara, T., \& Hibino G. (2012). A roadmap towards a low-carbon society in Japan using backcasting methodology: Feasible pathways for achieving an $80 \%$ reduction in $\mathrm{CO}_{2}$ emissions by 2050. Energy Policy, 41:584-598.

Bataille, C., Waisman, H., Colombier, M., Segafredo, L., Williams J. \& Jotzo F. (2016). The need for national deep decarbonization pathways for effective climate policy. Climate Policy.

Bernard, A., \& Vielle, M. (2008). GEMINI-E3, a general equilibrium model of international-national interactions between economy, energy and the environment. Computational Management Science, 5(3):173-206.

Böhringer, C., \& Müller, A. (2014). Environmental Tax Reforms in Switzerland. A Computable General Equilibrium Impacts Analysis. Swiss Journal of Economics and Statistics, 150(issue I):1-21. 
Bretschger, L. and Zhang L. (2016). Nuclear phase-out under stringent climate policies: A dynamic macroeconomic analysis. The Energy Journal, 38(1):167-194.

Deetman, S., Hof, A., Pfluger, B., van Vuuren, D., Girod, B., \& van Ruijven, B. (2013). Deep greenhouse gas emission reductions in Europe: Exploring different options. Energy Policy, 55:152-164.

Diamond, L., Leu, W., \& Chevalier, G. (2010). Potential for geological sequestration of $\mathrm{CO}_{2}$ in Switzerland. Bundesamt für Energie BFE.

E3MLab \& ICCS (2013). Ampere Assessment of Climate Change Mitigation Pathways and Evaluation of the Robustness of Mitigation Cost Estimates, 2013.

Edenhofer, O., Knopf, B., Barker, T., Baumstark, L., Bellevrat, E., Château, B., Criqui, P., Isaac, M., Kitous, A., Kypreos, S., Leimbach, M., Lessmann, K., Magné, B., Scrieciu, S., Turton, H., \& van Vuuren, D. (2010). The Economics of Low Stabilization: Model Comparison of Mitigation Strategies and Costs. The Energy Journal, 31(Special Issue 1):11-48, 2010.

Finkenrath, M. (2011). Cost and performance of carbon dioxide capture from power generation. International Energy Agency.

FOEN (2014). Swiss climate policy at a glance. Status and perspectives on the basis of Switzerland's 2014 report to the United Nations Climate Change Secretariat. The Federal Office for the Environment, Bern, 24 p.

International Energy Agency (2013). World Energy Outlook 2013.

International Energy Agency, (2008). $\mathrm{CO}_{2}$ capture and storage. A key carbon abatement option.

Mathy, S., Criqui, P., Knoop, K., Fischedick, M., \& Samadi, S. (2016). Uncertainty management and the dynamic adjustment of deep decarbonization pathways, Climate Policy.

Maire, S., Pattupara, R., Ramachandran, K., Vielle, M., \& Vöhringer, F. (2015). Electricity markets and trade in Switzerland and its neighbouring countries (ELECTRA), Econability, PSI, EPFL,

Narayanan, B., Aguiar, A., \& McDougall, R. (2012). Global Trade, Assistance, and Production: The GTAP 8 Data Base. Center for Global Trade Analysis, Purdue University.

Nathani, C., Sutter, D., van Nieuwkoop, R., Peter, M., Kraner, S., Holzhey, M., Rütter, H., \& Zandonella, R. (2011). Energy related disaggregation of the Swiss Input-Output Table, SFOE, EWG Publication, Bern.

Prognos (2012). Die Energieperspektiven für die Schweiz bis 2050 -Energienachfrage und Elektrizitätsangebot in der Schweiz 2000-2050, Basel.

Pye, S., \& Bataille, C. (2016). Improving deep decarbonization modelling capacity for developed and developing country contexts. Climate Policy.

Swiss Federal Office for the Environment (2015). Swiss Climate Reporting under the UNFCCC -Swiss Greenhouse Gas Inventories: Annual submissions under the UNFCCC on GHG emissions and removals in Switzerland.

Swiss Federal Office of Energy (2013). Schweizerische Gesamtenergiestatistik 2013 - overall energy statistics. 
Swiss Federal Office of Energy (2012). Potentiel des énergies renouvelables dans la production d'électricité.

Swiss Federal Office of Statistics (2010). Les scénarios de l'évolution de la population de la Suisse 2010-2060.

United Nations (2011). World Population Prospects: The 2010 Revision. Department of Economic United Nations and Population Division Social Affairs.

Weyant, J., Knopf, B., de Cian, E., Keppo, I., \& van Vuuren, D. (2013). Introduction to the EMF28 Study on scenarios for transforming the European energy system. Climate Change Economics, 4. 